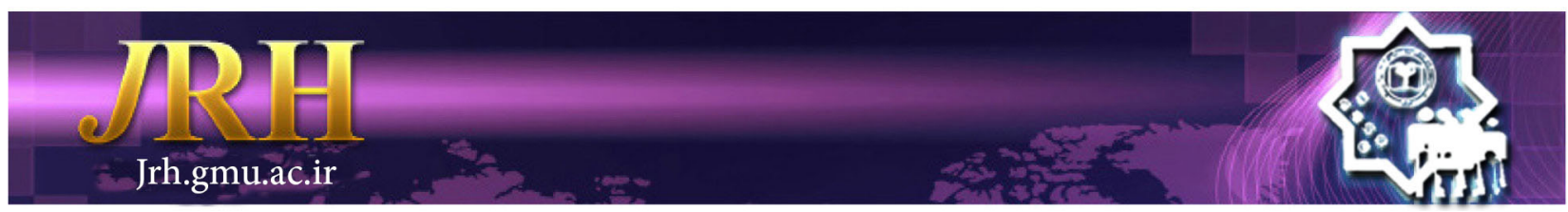

\title{
The effect of mindfulness training on reducing couple burnout of addict's wife
}

Reza Ghasemi Jobaneh ${ }^{1}$, Alimohammad Nazari ${ }^{2}$, Bagher Sanai Zaker ${ }^{3}$

\author{
Journal of Research \& Health \\ Social Development \& Health Promotion \\ Research Center \\ Vol. 8, No.6, Nov \& Dec 2018 \\ Pages: 506- 512 \\ DOI: $10.29252 / j r h .8 .6 .506$ \\ Original Article
}

\begin{abstract}
1. Department of Family Counseling, Faculty of Psychology and Educational Sciences, Kharazmi University, Tehran, Iran

2. Correspondence to: Department of Psychology, School of Nursing and Midwifery, Shahroud University of Medical Sciences, Shahrood, Iran

Email: amnazariy@yahoo.com

3. Department of Counseling, Faculty of Psychology and Educational Sciences, Kharazmi University, Tehran, Iran
\end{abstract}

Received: 8 Mar 2015

Accepted: 27 Jun 2015

How to cite this article: Ghasemi Jobaneh R, Nazari A, Sanai Zaker B. The effect of mindfulness training on reducing couple burnout of addict's wife. $J$ Research \& Health2018; 8(6): 506- 512.

\begin{abstract}
Addiction can cause many problems for the addict and family, so that the addict's family suffers from more problems. Addicts' wife suffer more psychological and marital problems. The aim of this study was to investigate the effect of mindfulness training on reducing couple burnout of addict's wife. The study was quasiexperimental that used the pretest-posttest whit control group. The population of this study was consisted the addicts' wife referring to the addiction treatment centers of Rasht city, Iran. 20 persons were assigned into experimental and control groups by using random sampling method $(\mathrm{n}=10)$. The experimental group participated in 8 sessions of mindfulness training and control group received no intervention. The data collected through Pines' Couple Burnout Measure (CBM). The results showed that there was significant differences between the pretest and posttest scores of the experimental group so mindfulness training could significantly reduce the couple burnout out of addict's wife. Thus, interventions based on this approach lead to decrease the marital problems of these women.
\end{abstract}

Keywords: Addiction, Burnout, Mindfulness, Women

\section{Introduction}

Drug addiction is a complex problem. Addiction creates many problems for the addict and owns family. Therefore, the families of addicts suffer from psychological problems [1]. Dissatisfaction with the spouse is one of the results of drug dependence [2]. The results of many studies also showed that women with addicted husbands suffer more from psychological problems [3-5].

When people feel that what they do is important and their actions and behaviors are effective, they do not feel burnout even if they are experiencing tough conditions [6]. Burnout defined as a sign of physical, emotional, and psychological exhaustion [7] and Burnout in couples is a gradual process, in which intimacy and love gradually fade away [8]. Physical exhaustion is associated with weakness and chronic fatigue. In the mental exhaustion, the person feels unworthiness, a sense of despair, frustration, and outrage. Emotional exhaustion is associated as well with negative emotions such as depression and anxiety [6]. Because of addiction, spouses with addicted husbands encounter numerous problems. Between what is expected and what is actually happening, they see a great conflict and therefore they experience burnout [2]. Because of addiction, the addict avoids to accept own responsibilities at 
home and to family [9]. Women with addicted husbands have to accept the responsibility of their husbands in addition to their duties. This responsibility is stressful for them, reduces their mental health, and discourages them from life [1]. A significant proportion of women with addicted husband suffer at least from a mental disorder such as depression and anxiety $[4,10]$. Moreover, due to husband's addiction, women are exposed to domestic violence, the risk of transmission of sexually transmitted diseases such as AIDS, and aggravating physical, mental, and emotional distress [9]. In addition, the marital conflict is very high in women with addicted husband [3].

Mindfulness-based training is in one of the interventions that can be effective and useful in reducing couple burnout [11,12]. Mindfulness means non-judgmental targeted attention, and to experience of the present moment [13]. Mindfulness teaches that instead of denying and rejecting unpleasant experiences, individuals accept them as they are and be aware about themselves and their reactions to unpleasant experiences [14]. Individual gains the insight that in the case of unpleasant events, instead of reactive and immediate behaviors, which usually lead to burnout they can cultivate a state of acceptance and awareness in every moment [13]. The results of many researches indicate that there is a significant relationship between mindfulness training and safe and satisfactory relationship in life [15-17]. Mindfulness makes people to act constructively in stressful situations [18]. The research results indicate that mindfulness-based therapy is effective in improving sexual function in women $[19,20]$. Furthermore, research findings showed that mindfulness training has been effective on couple burnout in women who have hyperactive children [11]. In another study, the results showed that mindfulness training could significantly contribute to reduce couple burnout and to increase marital happiness in married women referred to the counseling centers [12].

The results of a study showed that mindfulness training could help the infertile women to experience less negative inner states [21]. In another study, results showed that mindfulness reduces the stress of mothers of children with autism [22]. There is a significant negative relationship between mindfulness and psychological distress like depression, anxiety, stress [23], and aggression [24]. There is a positive relationship between mindfulness and balance between work and family, sleep quality, and vitality [25]. In a review study, it found that mindfulness has positive psychological effects [26].

Status of women with addicted husbands have a particular sensitivity according to their individual issues and their duties to the husband, children and society and paying special attention to this group is necessary [27]. Also, focusing on family members of addicts and their education and treatment can have a positive impact on the addict's recovery, and also improves family functioning [28].

Therefore, due to the negative impact of addiction on families and the great impact of couple burnout on quality of life in marriage and family dysfunctions, the aim of the present study is to determine the effect of mindfulness in reducing the burnout of married women with addicted husbands.

\section{Method}

The study was quasi-experimental and the pretest-posttest whit control group was used. The population in this study was women who were married to drug addicts and referred to addiction treatment centers of social welfare organization to get medical care and counseling in Rasht, the north of Iran, 2015. In this study, 20 women with addicted husbands selected after announcement for training course to reduce marital problems. The research was voluntary and their couple burnout scale score was higher than the average. They were selected by available sampling and randomly were assigned in both experimental and control groups $(n=10)$. Inclusion criteria consisted of being in the age range of 25-50, completing treatment consent form, lacking of psychological disorders, 
not being applicant of divorce, lacking of counseling and psychological treatment parallel of meetings, and at least one year for husband's addiction. In this study, in order to apply the independent variable, the experimental group participated in eight 120-minutes sessions of mindfulness training, while the control group did not receive any intervention. Before the implementation of the independent variable (mindfulness training), pretest (couple burnout measure) was performed. After the implementation of the independent variable, Couple Burnout Measure (CBM) performed again. The results of each experimental group compared with the control group. It explained to the participants that the group trainings is planned to reduce their marital problems and is a part of a research work. The issue of informed consent raised and they all participated with the full consent. Also after the training session and carrying out posttest in both control and experimental groups, in order to uphold the principles of research ethics, the control group also received the mindfulness training. To collect data, the following tools used:

Pines 'Couple Burnout Measure (CBM): In the present study, the 21-item measure of couple burnout used to investigate couple burnout that developed by Pines in 1996. It consists of three subscales: physical, mental, and emotional exhaustion. Taken together, the total score and subscales of couple burnout can be achieved. All questions answered on a 7-point Likert scale from one to seven. The high score is 147 and the lowest score is 21. A survey conducted in Iran [29] suggested that CBM has an acceptable validity and reliability.

In the present study, the goal of researchers was to exploit mindfulness-based trainings. To reach the goal, a combinative protocol based on two main streams of mindfulness (Mindfulness-Based Stress Reduction and Mindfulness-Based Cognitive Therapy) was used. [30].

The regular program of mindfulness training sessions was as follows:

Session I: Introducing of participants, providing explanations of addiction and the impact of addiction on the family members, discussion on couple burnout, the practice of eating raisins, talking about many people live unconsciously, body scan exercise.

Session II: Body scan exercise, inviting participants to talk about their experiences of the practice of mindfulness, obstacle investigation, a discussion of some features of mindfulness as a non-judgmental approach, thoughts and feelings exercise, practicing sitting meditation by focus on breathing.

Session III: Exercises of short seeing or hearing, sitting meditation by focusing on breathing and physical sense, threeminute breathing space, and mindful body movements.

Session IV: Sitting meditation with focusing on the breath, body, sounds and thoughts, discussion of stress and the common reactions of people in difficult situations, conscious walking.

Session V: Sitting meditation practice by focusing on the breath, body, sounds, and ideas, discussion on acknowledging and accepting the reality of the situation as it is now, practicing second series of mindful body movements.

Session VI: Three-minute breathing space, discussion about often non-factual thoughts.

Session VII: Sitting meditation practice and open awareness, discussion on the best way to care for self, assessment of daily activities related to pleasant activities vs. unpleasant activities and learn planning for pleasant activities, love and kindness meditative practice.

Session VIII: body scan exercise, discussion on what have been learned so far, usage, evaluation of training, supplement of more resources.

The collected data analyzed by using multivariate analysis of covariance (MANCOVA) with SPSS-18 software. The significance level in statistical tests was 0.01 .

\section{Results}

Twenty women with mean age of 36.88 and standard deviation of 4.88 participated in 
this study. Also $31.2 \%$ of the participants were under diploma, 50\% had diploma, and $18.8 \%$ were higher than diploma. The descriptive information of the variables provided in Table 1.

Table 1 Descriptive information (mean and standard deviation)

\begin{tabular}{lccccc}
\hline \multirow{2}{*}{ Variable } & & \multicolumn{2}{c}{ Pretest } & \multicolumn{2}{c}{ Posttest } \\
\cline { 2 - 6 } Physical exhaustion & Groups & $\mathrm{M}$ & $\mathrm{SD}$ & $\mathrm{M}$ & $\mathrm{SD}$ \\
\hline \multirow{2}{*}{ Psychological exhaustion } & Experimental & 23.30 & 2.54 & 20.30 & 1.41 \\
& Control & 23.00 & 2.90 & 23.90 & 2.55 \\
\hline \multirow{2}{*}{ Emotional exhaustion } & Experimental & 25.60 & 2.50 & 21.51 & 1.08 \\
& Control & 27.90 & 2.18 & 26.10 & 2.18 \\
\hline & Experimental & 30.70 & 2.62 & 28.50 & 2.41 \\
& Control & 29.40 & 2.01 & 30.70 & 2.79 \\
\hline
\end{tabular}

As can be seen in the Table above, the mean scores in the control group showed little difference but the difference is visible in the experimental group. Levine's test used to observe the assumptions of the covariance. Error variance of physical exhaustion $(\mathrm{F}=0.00$, $\mathrm{Sig}=0.97)$, mental exhaustion $(\mathrm{F}=2.12$, Sig $=0.16)$ and emotional exhaustion $(\mathrm{F}=0.4$, Sig=0.84) does not differ among participants (experimental and control group) and variances are equal. Moreover, Box's $M$ test used to study the homogeneity of the covariance. Results showed that Box's M was not significant, and therefore the assumption of difference between covariance is established $(\mathrm{F}=2.64, \mathrm{Sig}=0.15)$. The results of multivariate analysis of covariance shown in Table 2 and 3.

Table 2 Multivariate tests

\begin{tabular}{lccccc}
\hline Test & Value & F & Hypothesis df & Error df & Sig. \\
\hline Pillai's trace & 0.79 & 17 & 3 & 13 & 0.001 \\
Wilks' lambda & 0.20 & 17 & 3 & 13 & 0.001 \\
Hotelling's trace & 3.92 & 17 & 3 & 13 & 0.001 \\
Roy's largest root & 3.92 & 17 & 3 & 13 & 0.001 \\
\hline
\end{tabular}

Table2 shows that the observed $F$ for Pillai's Trace, Wilks' Lambda, Hoteling's Trace and Roy's Largest Root is 17 at a significance level

of 0.001 . This means that there is a significant difference at least in one of the comparable variables between the two groups.

\begin{tabular}{lcccccc}
\multicolumn{2}{l}{ Table 3 Tests of between-subjects effects } \\
\hline Dependent variable & Sum of squares & Df & Mean square & F & Sig. & Eta \\
\hline Physical exhaustion & 30.64 & 1 & 30.64 & 8.05 & 0.001 & 0.34 \\
Psychological exhaustion & 61.76 & 1 & 61.76 & 20.12 & 0.001 & 0.57 \\
Emotional exhaustion & 24.28 & 1 & 24.28 & 12.33 & 0.001 & 0.45 \\
\hline
\end{tabular}

The results showed that there is a significant difference between the groups in terms of couple burnout. This means that mindfulness training reduced in physical $(\mathrm{F}=8.05, \mathrm{p} \geq 0.001)$, psychological $\quad(\mathrm{F}=20.12, \quad \mathrm{p} \geq 0.001), \quad$ and emotional exhaustion $(\mathrm{F}=12.33, \mathrm{p} \geq 0.001)$ in the experimental group compared to the control group. Given the size of the effect, it can be stated that mindfulness training had the greatest impact on psychological exhaustion.

\section{Discussion}

Results showed that mindfulness training significantly reduced the couple burnout. These findings by consistent of other studies showed that mindfulness training could lead to decrease in couple burnout $[11,12]$. Several studies have shown that mindfulness-based interventions enhanced psychological well-being as well [23-26]. The interventions have also significant impact on reducing marital problems and improving the quality of marital life [15-17]. In addition, other studies have shown that mindfulness training help people especially in tough conditions, to adapt the harsh conditions in efficient and rational way and to deal with the 
challenges of life $[21,22]$.

One of the important features of mindfulness is to teach people to be aware of the events as they are rather than reacting to events immediately. In fact, people normally accustomed to react promptly to the thoughts, feelings, sensations, and emotions [13]. While the individuals are taught by doing exercises like focusing on breathing, body scan, sitting meditation, they become aware of their thought, feeling, and emotion when facing unpleasant experiences. The exercises generalized to daily life, and the individual gains the insight that in the case of unpleasant events, such as spouse's addiction, instead of reactive and immediate behaviors, which usually lead to burnout and its symptoms [31], individual should cultivate state of acceptance and awareness in every moment. This awareness has positive consequences. One of which will be mental peace and a person in a state of relaxation can make appropriate decisions, and instead of immediate responses, person can have constructive reaction. In mindfulness training, the women taught that instead of focusing on the past and the expectations they had, They should focus on present, and be aware of the current moment. In mindfulness, by doing exercises like focusing on breathing, body scan, sitting meditation, the individuals are taught to have a better relationship with own body, which helps to reduce many signs and symptoms of burnout and exhaustion.

In addition, in mindfulness training sessions, many points will offered, which help women to adapt and efficiently deal with the current situation that is unpleasant. For example, in relation to the usual stress and reactions to difficult situations, alternative attitudes and reactions and useful information provided. Information is given in relation to accepting the present reality and the best way to take care of yourself. Moreover, planning to do pleasant activities help women to activate those behaviors that reduce burnout.

In mindfulness training by practicing love and compassion, individuals learn not to judge others and foster a sense of compassion and kindness [32]. In fact, in mindfulness, individual learns to grow sense of compassion, kindness, and love not only to the family members, but also towards all creatures. A sense of acceptance, love, and kindness could be manifested towards the spouse and it can reduce the burnout and increase solidarity between them.

In confirming these findings, it can be noted that there is direct relationship between marital burnout and negative emotions such as depression and anxiety [33,34]. The results also showed that there is significant correlation between mindfulness and emotion regulation strategies and psychological wellbeing $[35,36]$. In fact, by using the techniques of mindfulness and its generalization to everyday life can make the individual to come along better with positive and negative emotions. When people live mindfully, they are better able to regulate their emotions and report less psychological problems such as depression and anxiety [35]. The study conducted on women with addicted husbands in Rasht and the generalization of the results to other populations should be done carefully. It recommended that similar studies can be carried out in other statistical societies especially populations that are somehow involved in marital or relationship problems. It is also recommended, with respect to the role of mindfulness in reducing couple burnout, this type of intervention can be conducted on other couples who are somehow involved in some conflicts and problems, for example, infertile couples. Also, in addiction treatment centers, in addition to treatment programs for addicts, spouses' problems should be considered, and educational and treatment programs can be provided to reduce their psychological and marital problems.

\section{Conclusion}

The results of this study indicated the importance of mindfulness training in reducing the burnout of married women with addicted husband. They are not in good condition in terms of psychological and marital status. By training appropriate skills, which their effects has been confirmed, these women can be helped by learning some skills and acceptance of the situation, and experience far less turbulent. As a result, they can foster the ability to make the 
right and constructive decision and they are better able to deal with the situation. Mindfulness-based interventions based on set of simple practices and principles help people have better performance. The techniques can be used in clinical and nonclinical positions require learning and continuous effort and practice.

\section{Acknowledgments}

This paper was extracted from Master's Thesis in Family Counseling, Faculty of Psychology and Education, Kharazmi University. We thank the women who participated in this study.

\section{Contribution}

Study design: RGH, AN, BS

Data collection and analysis: RGH

Manuscript preparation: $\mathrm{RGH}, \mathrm{AN}, \mathrm{BS}$

\section{Conflict of Interest}

"The authors declared that they have no competing interests"

\section{Funding}

The author (s) received no financial support for the research, authorship and/or publication of this article.

\section{References}

1- Taghavi Dinani P, Amiralsadat F, Samkhanian E, Zarbakhsh M, Baramsipour Z. Study the effectiveness of brief group interpersonal psychotherapy in reducing depressive symptoms of addict's spouses. Am Eurasian $J$ Agric Environ Sci2014; 14(4): 282-6.

2- Pirsaraee HY. Drug dependence and marital satisfaction: A qualitative study among users of opium and heroin in Iran. Asian Journal of Counselling2007; 14(1): 2-1.

3- Rahimpour R, Khankeh HR, Fallahi Khoshknab M, Farhoodian A, Farzi M. The evaluation of marital adjustment of the addicts in Isfahan NA groups and their couples. Iranian Rehabilitation Journal2012; 10(1): 13-7. 4- Mohammadkhani P. The personal-relationships problems of women how had addicted husband: A perspective to their rehabilitation. Journal of Research on Addiction2009; 3(9): 17- 36.

5- Pourmovahed Z, Dehghani H, Askari J. Factors responsible for addiction from the viewpoint of wives of addicts. Procedia Soc Behav Sci2013; 84 (9): 719 -22.

6- Pines AM, Neal MB, Hammer LB, Icekson T. Job burnout and couple burnout in dual-earner couples in the sandwiched generation. Soc Psychol Q2011; 74(4): 361-86.
7- IsHak WW, Lederer S, Mandili C, et al. Burnout during residency training: a literature review. J Grad Med Educ2009; 1(2): 236-42.

8- Zarei E, Sadeghifard M, Adli M, Tayebi Soogh M. The effectiveness of ellis couple therapy training (the rationalemotional-behavioral approach) on reducing the marital burnout. Journal of Life Science and Biomedicine2013; 3(3): 229-32.

9- Singh A. Strategies adopted by wives of addicts: A sociological study of women in rural Punjab, India. International Journal of Sociology and Anthropology2010; 2(8): 162-70.

10- Kishor M, Pandit LV, Raguram R. Psychiatric morbidity and marital satisfaction among spouses of men with alcohol dependence. Indian JPsychiatry2013; 55(4): 360 .

11- Sadat Motahhari Z, Ahmadi Kh, Behzadpoor S, Azmoodeh F. Effectiveness of mindfulness in marital burnout among mothers of ADHD children. Journal of Family Counseling and Psychotherapy2013; 3(4): 591- 613 .

12- Khodabakhsh Moghadam Z, Navabi Nejhad Sh, Ahmady Kh. Examining the effectiveness of group mindfulness-based cognitive therapy on marital burnout in married women in mental and emotional dimensions of Region 1 in Tehran. International Journal of Humanities and Cultural Studies 2016; 1: 2008-16.

13- Gehart DR. Mindfulness and acceptance in couple and family therapy. New York: Springer; 2012.

14- Crane R. Mindfulness-based cognitive therapy: Distinctive features. London: Routledge; 2017.

15- Atkinson BJ. Mindfulness training and the cultivation of secure, satisfying couple relationships. Couple and Family Psychology: Research and Practice2013; 2(2): 73-94.

16- Jones KC, Welton SR, Oliver TC, Thorburn JV. Mindfulness, spousal attachment, and marital satisfaction: a mediated model. J Fam Health2011; 19(4): 357- 61.

17- Burpee LC, Langer EJ. Mindfulness and marital satisfaction. J Adult Dev2005; 12(1): 43- 51.

18- Barnes S, Brown KW, Krusemark E, Campbell $\mathrm{WK}$, Rogge RD. The role of mindfulness in romantic relationship satisfaction and responses to relationship stress. J Marital Fam Ther2007; 33(4): 482-500.

19- Brotto LA, Basson R. Group mindfulness-based therapy significantly improves sexual desire in women. Behav Res Ther2014; 57: 43- 54.

20- Brotto LA, Erskine Y, Carey M, et al. A brief mindfulness-based cognitive behavioral intervention improves sexual functioning versus wait-list control in women treated for gynecologic cancer. Gynecol Oncol2012; 125(2): 320-5.

21- Galhardo A, Cunha M, Pinto-Gouveia J. MindfulnessBased Program for Infertility: efficacy study. Fertil 
Steril2013; 100(4): 1059- 67.

22- Conner CM, White SW. Stress in mothers of children with autism: Trait mindfulness as a protective factor. Res Autism Spectr Disord2014; 8(6): 617-24

23- Carmody J, Reed G, Kristeller J, Merriam P. Mindfulness, spirituality, and health-related symptoms. $J$ Psychosom Res2008; 64(4): 393-403.

24- Yusainy C, Lawrence C. Relating mindfulness and self-control to harm to the self and to others. Pers Individ Dif2014; 64: 78-83

25- Allen TD, Kiburz KM. Trait mindfulness and workfamily balance among working parents:The mediating effects of vitality and sleep quality. J Vocat Behav2012; 80(2): 372-9.

26-Keng SL, Smoski MJ, Robins CJ. Effects of mindfulness on psychological health: A review of empirical studies. Clin Psychol Rev2011; 31(6): 1041-56.

27- Talebi A, Tabatabaei S. The effect of life skills on family functions with addicted husband. Journal of Research on Addiction2011; 4(16): 25-40.

28- Liddle HA, Dakof GA, Parker K, Diamond GS, Barrett K, Tejeda M. Multidimensional family therapy for adolescent drug abuse: Results of a randomized clinical trial. Am J Drug Alcohol Abuse2001; 27(4): 651-88.

29- Navadi F. Surveying and comparison the relationship between couple burnout with organizational climate factors in staffs of education offices and the nurses of hospitals in Tehran. [Thesis]. Industrial psychology. Tehran: Shahid Beheshti University, 2006.

30- Van Son J, Nyklíček I, Pop VJ, Pouwer F. Testing the effectiveness of a mindfulness-based intervention to reduce emotional distress in outpatients with diabetes (DiaMind): design of a randomized controlled trial. BMC Public Health2011; 11(1): 131.

31- Pines AM, Nunes R. The relationship between career and couple burnout: Implications for career and couple counseling. J Employ Couns2003; 40(2): 50- 64.

32- Carson JW, Carson KM, Gil KM, Baucom DH. Mindfulness-based relationship enhancement. Behav Ther2004; 35(3): 471-94.

33- Ghavi F, Jamale S, Mosalanejad L, Mosallanezhad Z. A study of couple burnout in infertile couples. Glob $J$ Health Sci2016; 8(4): 158-65.

34- Ahola K, Hakanen J, Perhoniemi R, Mutanen P. Relationship between burnout and depressive symptoms: A study using the person-centered approach. Burn Res2014; 1(1): 29-37.

35- Hill CL, Updegraff JA. Mindfulness and its relationship to emotional regulation. Emotion2012; 12(1): 81-90.

36- Chambers R, Gullone E, Allen NB. Mindful emotion regulation: An integrative review. Clin Psychol Rev2009; 29(6): 560-72.

Copyright $\subset$ 2016 ASP Ins. This open-access article is published under the terms of the Creative Commons Attribution-NonCommercial 4.0 International License which permits Share (copy and redistribute the material in any medium or format) and Adapt (remix, transform, and build upon the material) under the Attribution-NonCommercial terms. 